\title{
Early cases of SARS-CoV-2 infection in Uganda: epidemiology and lessons learned from risk-based testing approaches - March-April 2020
}

Richard Migisha" ${ }^{*}$ D, Benon Kwesiga', Bernadette Basuta Mirembe², Geofrey Amanya', Steven N. Kabwama', Daniel Kadobera ${ }^{1}$, Lilian Bulage ${ }^{1}$, Godfrey Nsereko ${ }^{2}$, Ignatius Wadunde ${ }^{1}$, Tonny Tindyebwa ${ }^{3}$, Bernard Lubwama ${ }^{2}$, Atek A. Kagirita ${ }^{2}$, John T. Kayiwa ${ }^{4}$, Julius J. Lutwama ${ }^{4}$, Amy L. Boore ${ }^{5}$, Julie R. Harris ${ }^{5}$, Henry Kyobe Bosa ${ }^{4,6}$ and Alex Riolexus Ario ${ }^{1,2}$

\begin{abstract}
Background: On March 13, 2020, Uganda instituted COVID-19 symptom screening at its international airport, isolation and SARS-CoV-2 testing for symptomatic persons, and mandatory 14-day quarantine and testing of persons traveling through or from high-risk countries. On March 21, 2020, Uganda reported its first SARS-CoV-2 infection in a symptomatic traveler from Dubai. By April 12, 2020, 54 cases and 1257 contacts were identified. We describe the epidemiological, clinical, and transmission characteristics of these cases.
\end{abstract}

Methods: A confirmed case was laboratory-confirmed SARS-CoV-2 infection during March 21-April 12, 2020 in a resident of or traveler to Uganda. We reviewed case-person files and interviewed case-persons at isolation centers. We identified infected contacts from contact tracing records.

Results: Mean case-person age was $35( \pm 16)$ years; 34 (63\%) were male. Forty-five (83\%) had recently traveled internationally ('imported cases'), five (9.3\%) were known contacts of travelers, and four (7.4\%) were community cases. Of the 45 imported cases, only one (2.2\%) was symptomatic at entry. Among all case-persons, 29 (54\%) were symptomatic at testing and five (9.3\%) were pre-symptomatic. Among the 34 (63\%) case-persons who were ever symptomatic, all had mild disease: 16 (47\%) had fever, 13 (38\%) reported headache, and 10 (29\%) reported cough. Fifteen (28\%) case-persons had underlying conditions, including three persons with HIV. An average of 31 contacts (range, 4-130) were identified per case-person. Five (10\%) case-persons, all symptomatic, infected one contact each.

Conclusion: The first 54 case-persons with SARS-CoV-2 infection in Uganda primarily comprised incoming air travelers with asymptomatic or mild disease. Disease would likely not have been detected in these persons without the targeted testing interventions implemented in Uganda. Transmission was low among symptomatic persons and nonexistent from asymptomatic persons. Routine, systematic screening of travelers and at-risk persons, and thorough contact tracing will be needed for Uganda to maintain epidemic control.

Keywords: COVID-19, SARS-Cov-2, Epidemiology, Surveillance, Uganda

\footnotetext{
* Correspondence: rmigisha@musph.ac.ug

'Uganda Public Health Fellowship Program, Ministry of Health, Kampala, Uganda

Full list of author information is available at the end of the article
}

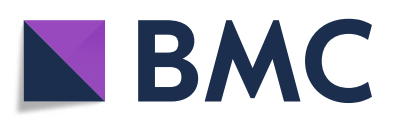

(- The Author(s). 2020 Open Access This article is licensed under a Creative Commons Attribution 4.0 International License, which permits use, sharing, adaptation, distribution and reproduction in any medium or format, as long as you give appropriate credit to the original author(s) and the source, provide a link to the Creative Commons licence, and indicate if changes were made. The images or other third party material in this article are included in the article's Creative Commons licence, unless indicated otherwise in a credit line to the material. If material is not included in the article's Creative Commons licence and your intended use is not permitted by statutory regulation or exceeds the permitted use, you will need to obtain permission directly from the copyright holder. To view a copy of this licence, visit http://creativecommons.org/licenses/by/4.0/ The Creative Commons Public Domain Dedication waiver (http://creativecommons.org/publicdomain/zero/1.0/) applies to the data made available in this article, unless otherwise stated in a credit line to the data. 


\section{Introduction}

COVID-19, the respiratory disease caused by severe acute respiratory syndrome coronavirus 2 (SARS-CoV-2) was first reported in Wuhan, China in late December 2019 [1]. On January 30, 2020, SARS-CoV-2 was declared a public health emergency of international concern, having spread to multiple countries outside of China [2]. By March 11, 2020, it was declared a global pandemic, with approximately 118,000 confirmed cases and nearly 4300 deaths on all continents except Antarctica [3]. However, Uganda had not yet reported any cases of SARS-CoV-2 infection.

On March 13, 2020, having noted the rapid spread of SARS-CoV-2 in most other countries in the world, Uganda instituted multiple measures to prevent entry and spread. These included symptom screening at the airport, isolation and testing for symptomatic persons, and a mandatory 14-day institutional quarantine and testing of travelers from high-risk countries [4]. Persons entering from low-risk countries [4] were asked to selfquarantine but were not tested unless they had symptoms on arrival. Travelers in quarantine were tested if they developed symptoms or on Day 14 of quarantine, regardless of symptoms. Effective March 23, 2020, the country implemented a ban on all international travel, and closed both schools and universities. One day later, the Ministry of Health requested all travelers entering Uganda the United Arab Emirates in the past two weeks to self-present for testing. Subsequently, all persons who had traveled from any international destination into Uganda since March 7 were asked to self-present for testing. On March 30, 2020, the country instituted a complete lockdown, banning all public transport and public gatherings.

On March 21, 2020, Uganda confirmed its first SARSCoV-2 infection in a Ugandan traveler from the United Arab Emirates. By April 15, 2020, 54 cases had been reported in country [5]. The country implemented thorough contact tracing for all infected persons. We describe the interventions in place and the characteristics of and transmission from the first 54 case-persons to provide guidance for near-future interventions against SARS-CoV-2 spread in Uganda.

\section{Methods}

\section{Case definition and study procedures}

We defined a confirmed case as laboratory-confirmed SARS-CoV-2 infection identified during March 21-April 12,2020 in a resident of or traveler to Uganda. A suspected case was defined as onset of acute respiratory illness with high temperature (above $37.5^{\circ} \mathrm{C}$ ) and at least one sign/symptom of respiratory illness (e.g., cough, shortness of breath), AND a history of travel to or residence in a location reporting community transmission of SARS-CoV-2 during the last 14 days prior to symptom onset, in a resident or traveler to Uganda from March 21April 12, 2020. Laboratory testing of oropharyngeal and/ or nasopharyngeal swabs was done at Uganda Virus Research Institute (UVRI) using real-time RT-PCR (Berlin protocol) [6]. All confirmed case-persons were isolated in hospitals. We reviewed case files and interviewed all casepersons at isolation centers located within four hospitals treating case-persons: Mulago National Referral Hospital, Entebbe Grade B Hospital, Adjumani General Hospital, and Hoima Regional Referral Hospital (Fig. 1). All casepersons were tested for HIV on entry and were asked about other underlying diseases. We also conducted a telephone interview with one case-person who was isolated and being managed at home.

\section{Assessment of symptoms}

We assessed for presence of symptoms during the 14 days preceding sample collection/testing. All case-persons were subsequently monitored for development of new symptoms while admitted in hospital using a self-monitoring tool for symptoms. We categorized case-persons as symptomatic if they had had any new or worsened typical or atypical COVID-19 symptom in the previous 14 days. We classified case-persons as having typical symptoms if they had temperature greater than $37.5^{\circ} \mathrm{C}\left(99.5^{\circ} \mathrm{F}\right)$ or selfreported fever, shortness of breath, or cough [7]. We categorized case-persons as having atypical symptoms if they had at least one of the following: chills, confusion/irritability, body weakness, nasal congestion, runny nose, sore throat, joint pains, muscle pains, chest pain, dizziness, headache, abdominal pain, nausea, or diarrhea without any of the typical symptoms [7]. We classified casepersons as asymptomatic if they had no new symptoms or no worsening chronic symptoms (e.g., stable chronic cough). Presymptomatic case-persons were those who were asymptomatic at the time of sample collection but developed symptoms within the 14days of isolation/admission. Case-persons who did not develop any new symptoms in the 14 days after isolation were still classified as asymptomatic.

\section{Tracing of contacts}

Contacts were defined as persons with face-to-face contact $(<2 \mathrm{~m})$ with a case-person or persons who spent time in a closed environment with a case-person, including coworkers or household members; healthcare workers or other persons providing direct care for case-persons without recommended personal protective equipment; persons sitting within 5 seats in any direction from the case-person in a vehicle or plane; or crew working in the section of the plane or vehicle where a case-person was seated. For symptomatic case-persons, all persons exposed to the case-person from two days before to 14 days after 


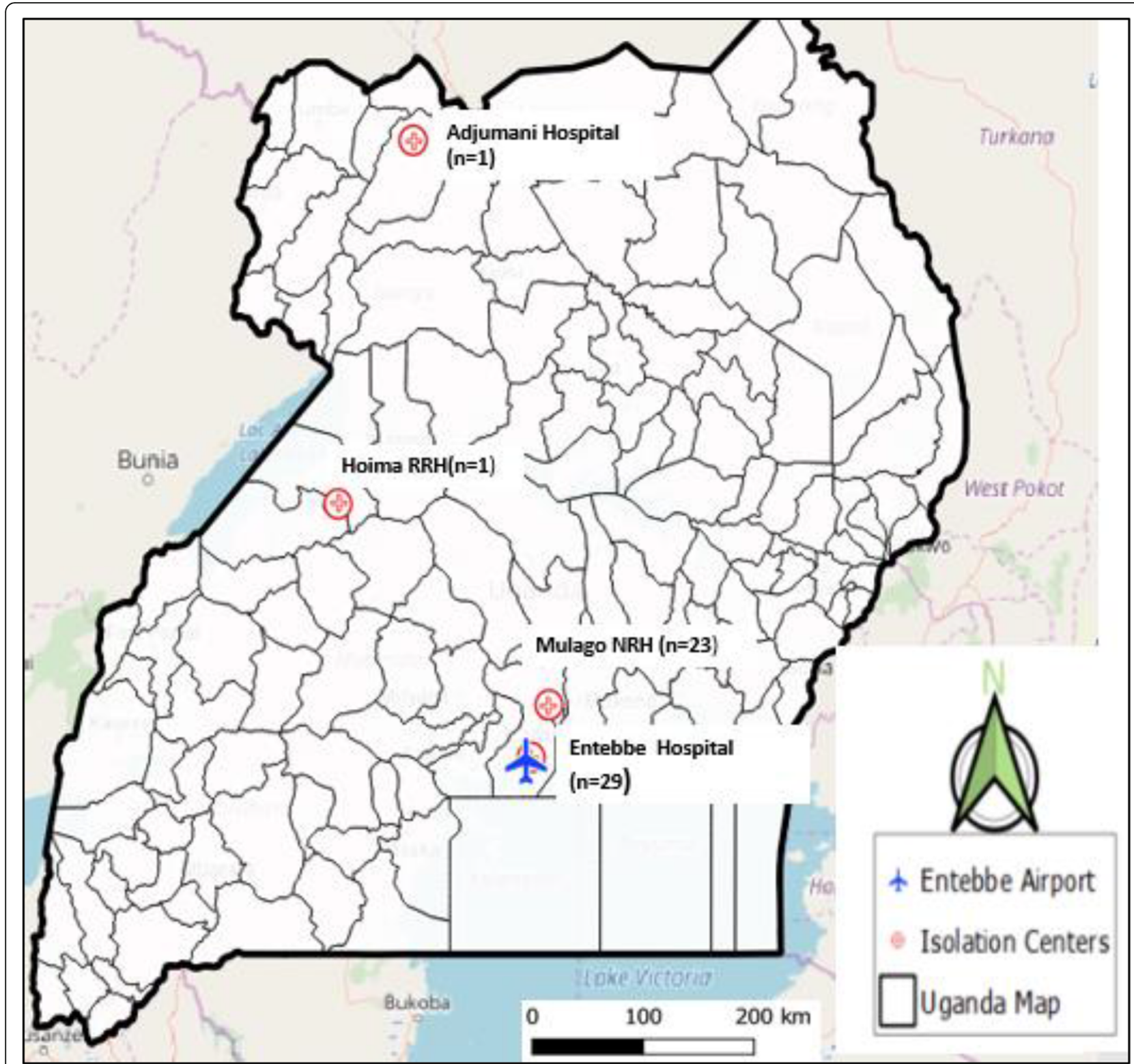

Fig. 1 Hospitals that managed the initial 54 persons with SARS-CoV-2 infection in Uganda, March-April, 2020 (map drawn using QGIS browser 3.10.2)

the case-person's symptom onset were listed as contacts as per Ministry of Health guidelines. For asymptomatic case-persons, all contacts exposed to the case-person in the 14 days before the case-person's laboratory confirmation were listed as contacts. This was done to account for our inability to identify the infectious period for asymptomatic case-persons. Contacts were initially tested just before release from quarantine, or any time they developed symptoms; however, guidance changed during the period to include a test midway through quarantine as well. We reviewed contact tracing records to identify the number of contacts per case.

\section{Statistical analyses}

Data were entered and analyzed in Epi Info 7.2. Software (CDC, Atlanta, USA). We described method of case-person identification as well as epidemiologic, demographic, and clinical characteristics of casepersons. Continuous variables were presented as means (SD) if they were normally distributed or medians (IQR) if they were not, and categorical variables as frequencies (\%). The clinical outcomes of the casepersons were described through April 12, 2020. For asymptomatic cases, we considered date of sample collection as a proxy for date of illness onset. 


\section{Results}

A total of 5025 tests for SARS-CoV-2 had been carried out in Uganda as of April 12, 2020. Of these, samples from 54 (1.1\%) persons were positive for SARS-CoV-2. From these 54 case-persons, 1257 contacts were identified. A total of 1105 high-risk travelers had been placed in institutional quarantine as of April 12, 2020, of whom $861(78 \%)$ had been discharged by that date.

\section{Demographics}

The mean age of the case-persons was $35( \pm 16)$ years, with a range of 7-66 years (Table 1); 34 (63\%) were male. Most (91\%) were Ugandan and 45 (83\%) had history of international travel, mainly to United Arab Emirates and United Kingdom (Table 1). Of 37 case-persons who shared their occupation, 19 (51\%) were in business (mainly dealing with imports/exports).

\section{Clinical characteristics of case-persons}

Among the 34 case-persons who eventually developed symptoms, $47 \%$ reported fever, 38\% reported headache, and 29\% reported cough (Table 2). Among all 34 symptomatic case-persons, only one (3\%) had all three typical symptoms of COVID-19 (Table 2). None of the casepersons developed severe disease requiring supplemental oxygen, intensive care, or life support, and none died.

Approximately three-quarters of the case-persons had no known underlying illnesses. Among 15 (28\%) case-persons with underlying disease, six had hypertension alone, four had diabetes alone, two had HIV alone, and one had a preexisting malignancy. In addition, one patient had both HIV and diabetes, and one had hypertension and diabetes. One case-person was pregnant in her third trimester at the time she was diagnosed with COVID-19 (Table 2).

\section{Case-person identification by location}

Of the 54 case-persons, 45 (83\%) were persons who had traveled in the past 14days. Among these, one was symptomatic and identified during airport screening when he entered the country (from Dubai), and had been sent directly from the airport to a testing site (Fig. 2).

An additional 25 were sent to institutional quarantine after returning from countries that had been categorized by Uganda as high-risk. Of these, 10 (40\%) case-persons became symptomatic while in quarantine and were tested as a result, while $15(60 \%)$ were identified during routine testing of asymptomatic persons in institutional quarantine. All remaining 19 travelers had come in from countries categorized as low-risk [4] and self-presented following a request from the Uganda Ministry of Health that recent travelers present for testing. Ten $(50 \%)$ of the travelers who tested positive after this request came from the United Arab Emirates.
Table 1 Demographic characteristics of first 54 persons with SARS-CoV-2 infection admitted to hospitals in Uganda

\begin{tabular}{|c|c|c|}
\hline Characteristic & $\begin{array}{l}\text { Total }(N=54) \\
n\end{array}$ & $\%$ \\
\hline \multicolumn{3}{|l|}{ Age $^{a}$ category } \\
\hline 0-9 Years & 4 & 7 \\
\hline 10-19 Years & 4 & 7 \\
\hline 20-29 Years & 11 & 20 \\
\hline 30-39 Years & 18 & 33 \\
\hline 40-49 Years & 6 & 11 \\
\hline 50-59 Years & 6 & 11 \\
\hline 60 years $\&$ above & 8 & 15 \\
\hline Male Sex & 34 & 63 \\
\hline Ugandan & 39 & 91 \\
\hline Chinese & 2 & 4 \\
\hline Congolese & 1 & 2 \\
\hline Canadian & 1 & 2 \\
\hline Resident in Uganda & 51 & 95 \\
\hline \multicolumn{3}{|l|}{ Occupation } \\
\hline Business & 19 & 35 \\
\hline Employed/civil servant & 6 & 11 \\
\hline Transporter & 3 & 6 \\
\hline Farmer & 2 & 4 \\
\hline Student & 1 & 2 \\
\hline Others & 6 & 11 \\
\hline Not disclosed & 17 & 31 \\
\hline \multicolumn{3}{|l|}{ Marital status } \\
\hline Single & 25 & 46 \\
\hline Married/Living with partner & 29 & 54 \\
\hline Contact with confirmed COVID-19 case & 17 & 32 \\
\hline International travel history (Imported cases) & 45 & 83 \\
\hline United Arab Emirates & 18 & 40 \\
\hline United Kingdom & 14 & 31 \\
\hline Turkey & 2 & 4 \\
\hline USA & 2 & 4 \\
\hline Other countries $^{\mathrm{b}}$ & 9 & 20 \\
\hline
\end{tabular}

${ }^{\text {a }}$ Mean (SD) age of $35( \pm 15.9)$ years

bone person each traveled to Canada, China, Afghanistan, South Sudan, Kenya, Rwanda, Ethiopia, Germany, and The Netherlands

Among the nine case-persons who did not travel, five were identified through contact tracing in the community; two $(40 \%)$ were symptomatic at the time of identification. The remaining four were identified at the health facility as part of routine screening of those who met definition for suspected COVID-19 case. Most of the case-persons were residents of the Kampala capital city (43\%) and its periurban neighboring district, Wakiso (24\%). 
Table 2 Clinical characteristics of first 54 persons with SARSCoV-2 infection admitted to hospitals in Uganda

\begin{tabular}{|c|c|c|}
\hline Characteristic ( $n=54$ cases) & $n$ & $\%$ \\
\hline \multicolumn{3}{|l|}{ Onset of symptoms } \\
\hline Symptomatic at sample collection & 29 & 54 \\
\hline Became symptomatic after sample collection & 5 & 9 \\
\hline Never became symptomatic at all & 20 & 37 \\
\hline Had underlying medical condition & 15 & 28 \\
\hline \multicolumn{3}{|l|}{ Comorbidities $^{c}(n=15)$} \\
\hline Hypertension & 6 & 40 \\
\hline Diabetes mellitus & 4 & 27 \\
\hline HIV & 2 & 13 \\
\hline Pre-existing malignancy & 1 & 7 \\
\hline HIV \& diabetes mellitus & 1 & 7 \\
\hline Hypertension \& diabetes mellitus & 1 & 7 \\
\hline Pregnant & 1 & 2 \\
\hline \multicolumn{3}{|l|}{ Symptoms $(n=34)$} \\
\hline Fever $^{a}$ & 16 & 47 \\
\hline Headache & 13 & 38 \\
\hline Cough $^{\mathrm{ab}}$ & 10 & 29 \\
\hline Runny nose $^{b}$ & 8 & 23 \\
\hline Chest pain ${ }^{b}$ & 6 & 18 \\
\hline Chills & 4 & 12 \\
\hline Shortness of breath ${ }^{\mathrm{ab}}$ & 3 & 9 \\
\hline Sore throat ${ }^{b}$ & 3 & 9 \\
\hline Nausea & 3 & 9 \\
\hline Diarrhe & 3 & 9 \\
\hline Joint pains & 2 & 6 \\
\hline Irritability or confusion & 2 & 6 \\
\hline Vomiting & 1 & 3 \\
\hline Abdominal pain & 1 & 3 \\
\hline \multicolumn{3}{|l|}{ Symptom classification $(n=34)$} \\
\hline Any one typical $\left.\right|^{a}$ symptom & 22 & 65 \\
\hline Two typicala symptoms & 6 & 18 \\
\hline All three typical ${ }^{a}$ symptoms & 1 & 3 \\
\hline Any respiratory ${ }^{b}$ symptoms & 16 & 47 \\
\hline Only atypical symptoms & 12 & 35 \\
\hline \multicolumn{3}{|c|}{ Treatment outcome at time of manuscript-writing } \\
\hline Recovered & 46 & 85 \\
\hline Still in isolation & 8 & 15 \\
\hline Admitted to intensive care unit & 0 & 0 \\
\hline Died & 0 & 0 \\
\hline
\end{tabular}

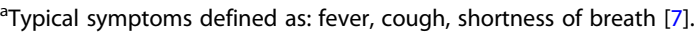
${ }^{b}$ Respiratory symptoms defined as: cough, chest pain, shortness of breath, runny nose and sore throat;

'Comorbidities: HIV Hypertension, Diabetes mellitus, Malignancy

\section{Description by time}

Illness onsets ranged from March 17 to April 6, 2020, with the highest number of case-persons having illness onset (or sample-taking, for asymptomatic patients) on March 22, 2020 (Fig. 3).

\section{Contact tracing}

Contact tracing was carried out for all case-persons. Of the 1257 contacts identified as of April 12, 2020, 1244 (99\%) were followed up. Of these, 603 (49\%) had completed the mandatory 14-day follow-up period and had been discharged from daily follow up. An average of 31 contacts (range, 4-130) were identified for each caseperson. Contacts were tested for SARS-CoV-2 a mean of 1.3 times (range, 1-3 times); five contacts tested positive.

\section{Transmission dynamics among initial cases in Uganda}

Among 20 asymptomatic case-persons, no forwardtransmission chains within Uganda were identified. Among 34 symptomatic case-persons, five (15\%) transmitted infection to a single person each. Nine (17\%) of the 54 case-persons spent between 1 and 12 (median: 4) days symptomatic in the Ugandan community before isolation, and of these, three (33\%) transmitted infection. Infection was also transmitted from two case-persons to others after developing symptoms in quarantine. In a single cluster of 11 case-persons, transmission could not be conclusively stated to have occurred in Uganda, as all had been traveling together previously in the United Kingdom and had traveled back Uganda on the same flight. All had become ill within one incubation period of travel (travel back to Uganda on March 20, 2020; onsets on March 20-March 31, 2020). Four of the confirmed case-persons, all of whom were symptomatic and identified as suspected cases at presentation at health facilities, had no history of travel and no known contact with a confirmed case.

\section{Discussion}

We describe the epidemiological characteristics of the initial 54 persons with confirmed SARS-CoV-2 infection in Uganda. Most (83\%) cases were imported, had atypical symptoms or few symptoms, with nearly half of patients being asymptomatic. Many of the early cases in Uganda, including the index case, were in persons who had traveled to countries not previously known to be high-risk [4], and were therefore not required to be in institutional quarantine. Despite extensive contact tracing and testing of contacts, few transmissions were identified.

Other countries have reported lower proportions of asymptomatic patients among their initial cases [8-13]. The high proportion of asymptomatic cases in Uganda is undoubtedly due to the national strategy, implemented 


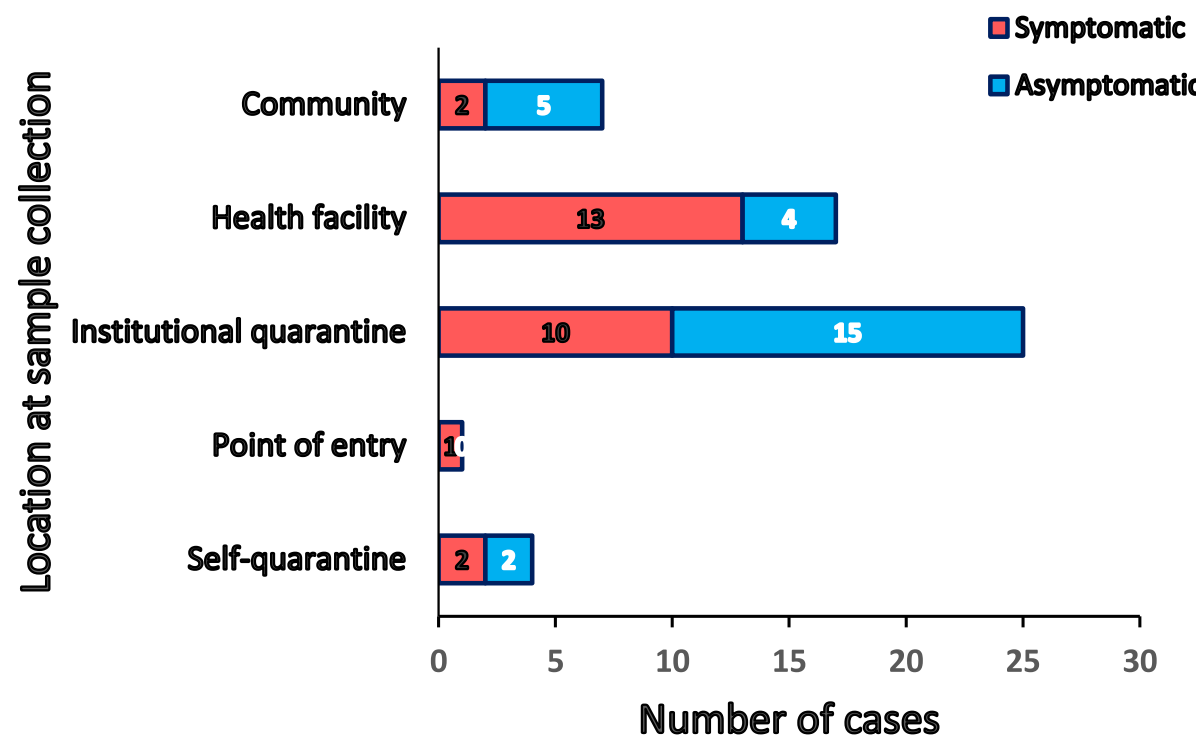

Fig. 2 Location of case-persons with SARS-CoV-2 infection at the time of sample collection, by symptom status, Uganda, 2020

on March 13, 2020, of testing all incoming travelers from high-risk countries and subsequently recalling and testing travelers from all countries, regardless of symptoms. As one of the last countries to be affected by COVID-19 globally, Uganda benefitted from the knowledge accrued during outbreaks in other settings and selected an initial testing strategy based on risk rather than presentation with symptoms, as was used in many other countries. This strategy had positive public health implications for Uganda and allowed detection of cases that would otherwise have been missed and could potentially have escalated community transmission. Recent data has shown that much SARS-CoV-2 transmission occurs from pre-symptomatic patients [14-18], suggesting that

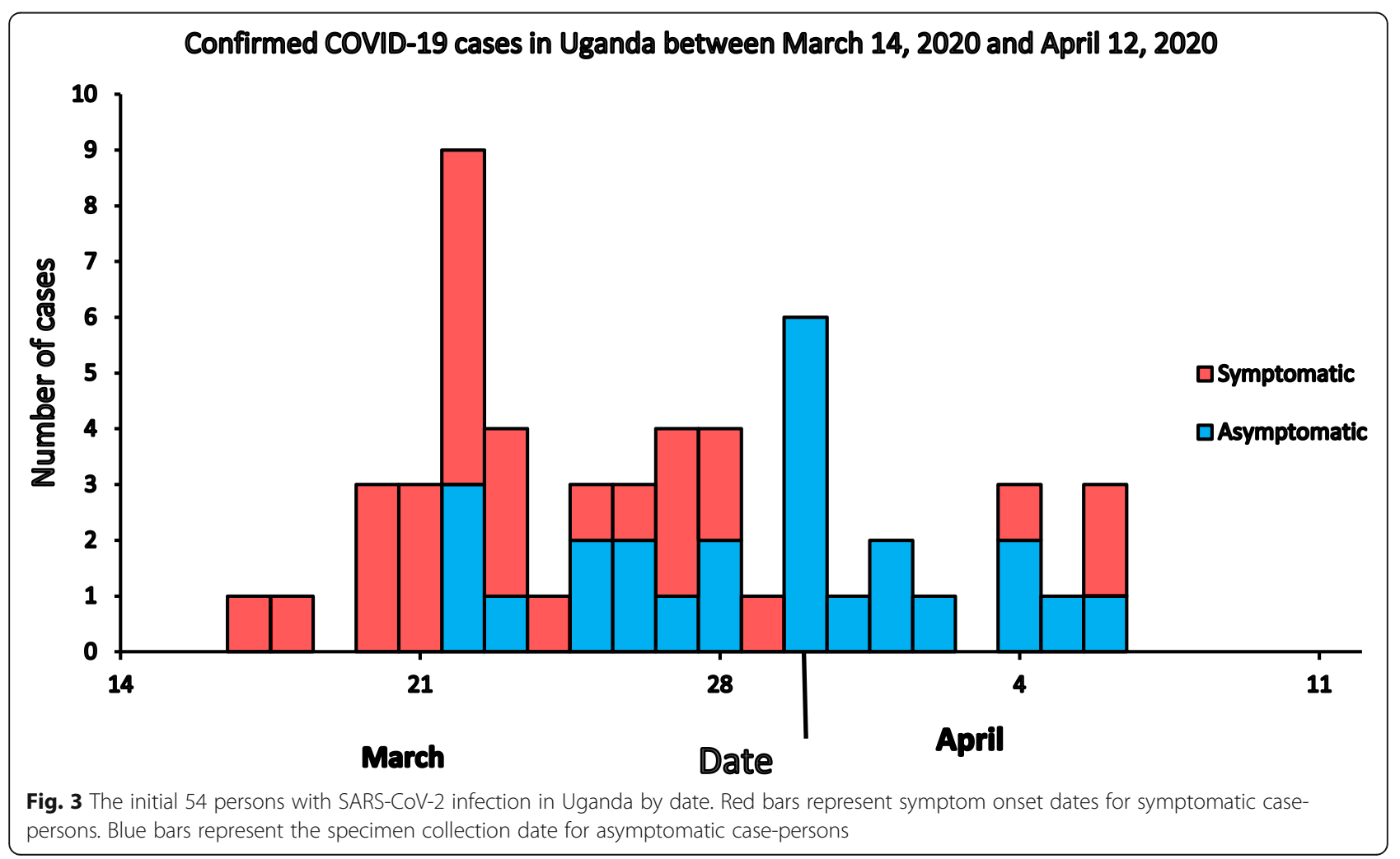


the earlier an infected person can be detected - even an asymptomatic case - the more effectively transmission can be prevented [19]. Our transmission data appear to reflect this, with only five transmission chains identified from the 54 confirmed cases. The use of a primarily risk-based rather than primarily symptom-based testing strategy also likely accounts for why, as of early May, Uganda still had fewer cumulative cases than its neighboring countries [20].

Similarly, none of the case-persons developed severe disease or died. This contrasts with the outcomes of initial cases from most other countries [8, 21-24]. This is also likely due to differential case ascertainment approach used in Uganda, compared with other countries. The majority of case-persons in this evaluation were unlikely to have been identified without active, targeted, risk-based testing. This is consistent with accruing data from around the globe demonstrating that an even higher proportion of cases than initially suspected are asymptomatic or are minimally symptomatic [25-27]. The relatively young age of most case-persons in Uganda may also have contributed to the outcomes, however. Severity of the disease is known to increase with advanced age and co-morbidities [8, 28, 29]. The mean age of our case-persons was 35 years. In contrast, in Italy, where the case-fatality rate was $12 \%$ in mid-March 2020 , the median age of the COVID-19 patients was 64 years $[30,31]$. Although approximately two-thirds of the casepersons were male, this is likely a result of a gender bias in incoming travelers, many of whom were businessmen, rather than a meaningful epidemiologic pattern specific to Uganda.

The main source of the outbreak in Uganda was returnees entering the country through Entebbe airport. At the time the first case-person was identified in Uganda, having traveled from Dubai, the United Arab Emirates was not recognized as a 'high-risk' country. Subsequently, many other travelers from Dubai to Uganda, as well as to other countries, were recognized as being infected [32]. Understanding the risk posed by travelers from specific countries, especially in the face of high proportions of persons with asymptomatic SARSCoV-2 infection and heterogeneous test availability and testing strategies, is a challenge. Countries that want to maintain a high degree of risk management - particularly those that manage to control transmission after an initial SARS-CoV-2 outbreak - may want to consider mandatory testing for all travelers at points of entry.

With the closure of the airport for commercial travel on March 21, 2020, the risk for SARS-CoV-2 infection in Uganda has shifted to other points of entries, at land borders. Porous borders in particular pose a major risk in Uganda, as they did with Ebola [33]. Focusing of strict border security and screening interventions, including testing of all persons crossing the border, is critical to the continued protection of Uganda. Identification of community-based approaches to ensure identification and testing of persons traveling through informal crossings will also be critical. For a coordinated strategy across East African regional member states to the COVID-19 pandemic, such as uniform application of testing strategies, could also facilitate improved control in the region.

Despite Uganda's efforts to prevent and control this pandemic, the high prevalence of asymptomatic infections will present a major challenge to continuing to keep the disease at bay. Traditional public health disease control and prevention strategies rely heavily on early disease detection, usually through identification of symptomatic persons, to contain spread. The fact that only one patient in this series had all the 'typical' features [7] of COVID-19 disease suggests that the Ministry of Health will need to rely on a high index of suspicion for the disease among the high-risk populations, regardless of their symptomatology. Consideration should be placed on routine testing of highrisk groups, even when asymptomatic, as well as mass community testing in priority settings if community transmission is suspected. Including asymptomatic individuals, especially for enclosed populations (schools, prisons, refugee settlements), into the screening algorithm for SARS-CoV-2 infection will require scaling-up and subsequent decentralization of testing in the country. Furthermore, these data support expanded symptom screening to improve early detection of cases in Uganda, given that a significant proportion of the symptomatic case-persons had atypical presentations. Delayed diagnosis, often as a result of few or no symptoms, are contributing factors to sustained community transmission of influenza-like illnesses $[34,35]$. While few transmissions occurred in our small case series, none were identified from asymptomatic persons. Continued intensive contact tracing, as shown in other places [36, 37], will be needed to continue to control the epidemic in Uganda.

Our findings are subject to some limitations. We analyzed data from only 54 case-persons in a setting of low community transmission. This may not give comprehensive understanding of the disease or the trajectory of the epidemic in Uganda. In addition, little community testing was occurring at the time outside of contact tracing testing, meaning that we may have underascertained cases.

\section{Conclusion}

The first 54 case-persons in Uganda with SARS-CoV-2 infection were primarily imported and had asymptomatic or mild disease. Transmission was low, even from 
symptomatic persons; asymptomatic persons did not transmit infection. Targeted testing interventions and other interventions implemented in Uganda enabled detection of these infected persons and likely enabled early disease control in Uganda in the setting of the initial phase of COVID-19 pandemic.

\section{Recommendations}

The Ministry of Health should consider intensifying routine and systematic screening of travelers and at-risk persons and emphasize thorough contact tracing. Increasing targeted testing among persons with a wider range of symptoms than is typically considered for COVID-19 should also be undertaken. Uganda must strengthen control measures at the points of entry to include routine and mandatory screening for SARS-CoV-2 for all travelers regardless of their symptomatology or origin, to minimize the risk of importation of the disease with subsequent community transmission.

\section{Abbreviations}

COVID-19: Coronavirus Disease; HIV: Human Immunodeficiency Virus; IQR: Inter-quartile Range; MoH: Ministry of Health; NRH: National Referral Hospital; RRH: Regional Referral Hospital; SARS-CoV-2: Severe Acute Respiratory Syndrome Coronavirus 2; SD: Standard Deviation; UVRI: Uganda Virus Research Institute

\section{Acknowledgments \\ We thank the patients who participated in this investigation. We are also very grateful to the support from the medical teams working with the confirmed cases in the isolation facilities in Uganda. We equally thank the administration of Mulago National Referral Hospital, Entebbe Grade B Hospital, Adjumani Hospital and Hoima Regional Referral Hospital for their support in conducting this investigation.}

\section{Disclaimer}

The findings and conclusions in this report are those of the authors and do not necessarily represent the views of the Centers for Disease Control and Prevention.

\section{Authors' contributions}

R.M, I. W, B. K, S.N.K, J. H, T.T., B.B.M, D. K, H.B.K, A.R.A, contributed to investigation, and drafted the first manuscript. G. A, I.W, L. B, R. M, B.B.W, G. N, did formal analyses. B. L, R. M, I. W, J.T.K, T. T, B.B.W, A.A.K, H.B.K, contributed to epidemiological data collection. J. H, A.L.B, and A.R.A, contributed to interpretation of findings. All authors contributed to the write up, and all read and approved the final manuscript.

\section{Funding}

This work was funded by the Cooperative Agreement-Provision of Comprehensive HIV/AIDS services and Developing National Capacity to manage HIV/AIDS Programs in the Republic of Uganda under the President's Emergency Plan for AIDS Relief (Cooperative Agreement number U2GGH001353-04) through the United States Centers for Disease Control and Prevention to Uganda Ministry of Health through Makerere University School of Public Health. The funder had no role in the design of the study, collection of data or decision to publish the work.

\section{Availability of data and materials}

The data sets and the reports that support this write up belong to the $\mathrm{MoH}$ Uganda. For reasons of confidentiality, the datasets and reports are not publicly available. However, datasets and the reports could be availed upon reasonable request and with permission from the $\mathrm{MoH}$ Uganda.

\section{Ethics approval and consent to participate}

This was a public health emergency and the Ministry of Health $(\mathrm{MoH})$ gave the directive to conduct epidemiological investigations for on persons with SARS-CoV-2 infection in the country. The investigation directive from $\mathrm{MoH}$ applied to all confirmed cases; however, we sought verbal consent from respondents in their respective languages during data collection. Participants were told that their participation was voluntary and that there would be no negative consequences if they refused to participate (none declined). During data collection, respondents were assigned unique identifiers instead of names to protect their confidentiality. Information was stored in passwordprotected computers and was not shared with anyone outside the investigation team. As this was a public health emergency, disclosure of patient information for the purposes of contact tracing was limited to the minimum needed to conduct contact tracing activities.

The Office of the Associate Director for Science, U.S. Centers for Disease Control and Prevention, determined that this activity was in response to a public health emergency with the primary intent of public health practice (epidemic disease control activity). It was determined therefore to not be human subjects research.

\section{Consent for publication}

Not applicable.

\section{Competing interests}

The authors declare they have no competing interest.

\section{Author details}

${ }^{1}$ Uganda Public Health Fellowship Program, Ministry of Health, Kampala, Uganda. ${ }^{2}$ Ministry of Health, Kampala, Uganda. ${ }^{3}$ Makerere University School of Public Health, Kampala, Uganda. ${ }^{4}$ Uganda Virus Research Institute, Entebbe, Uganda. ${ }^{5}$ US Centers for Disease Control and Prevention, Kampala, Uganda. ${ }^{6}$ Uganda People's Defence Forces, Kampala, Uganda.

Received: 20 July 2020 Accepted: 13 November 2020

Published online: 25 November 2020

\section{References}

1. Shi H, Han X, Jiang N, Cao Y, Alwalid O, Gu J, et al. Radiological findings from 81 patients with COVID-19 pneumonia in Wuhan, China: a descriptive study. Lancet Infect Dis. 2020.

2. Organization WH. COVID 19 public health emergency of international concern (PHEIC). Global research and innovation forum: towards a research roadmap 2020.

3. Cucinotta D, Vanelli M. WHO Declares COVID-19 a Pandemic. Acta Biomed. 2020 2020/03//; 91(1):[157-160 pp.]. Available from: http://europepmc.org/ abstract/MED/32191675. https://doi.org/10.23750/abm.v91i1.9397.

4. Update on Uganda's Enhanced Measures to Prevent Importation of Novel Corona Virus Disease COVID - 19 [press release]. Kampala, 13th March 2020 https://www.health.go.ug/covid/document/update-on-ugandas-enhancedmeasures-to-prevent-importation-of-novel-corona-virus-disease-covid-19/.

5. WHO. Coronavirus disease 2019 (COVID-19) Situation Report - 86. World Health Organisation website: World Health Organisation, 2020.

6. Corman V, Bleicker T, Brünink S, Drosten C, Zambon M. Diagnostic detection of 2019-nCoV by real-time RT-PCR. World Health Org. 2020:17.

7. Arons MM, Hatfield KM, Reddy SC, Kimball A, James A, Jacobs JR, et al, Presymptomatic SARS-CoV-2 infections and transmission in a skilled nursing facility. N Engl J Med. 2020..

8. Wu Z, McGoogan JM. Characteristics of and important lessons from the coronavirus disease 2019 (COVID-19) outbreak in China: summary of a report of 72314 cases from the Chinese Center for Disease Control and Prevention. JAMA. 2020;323(13):1239-42.

9. Chen N, Zhou M, Dong X, Qu J, Gong F, Han Y, et al. Epidemiological and clinical characteristics of 99 cases of 2019 novel coronavirus pneumonia in Wuhan, China: a descriptive study. Lancet. 2020;395(10223):507-13.

10. Livingston E, Bucher K. Coronavirus disease 2019 (COVID-19) in Italy. JAMA. 2020;323(14):1335

11. Pung R, Chiew CJ, Young BE, Chin S, Chen MI, Clapham HE, et al. Investigation of three clusters of COVID-19 in Singapore: implications for surveillance and response measures. Lancet. 2020.

12. Mizumoto K, Kagaya K, Zarebski A, Chowell G. Estimating the asymptomatic proportion of coronavirus disease 2019 (COVID-19) cases on board the 
diamond princess cruise ship, Yokohama, Japan, 2020. Eurosurveillance. 2020;25(10):2000180.

13. Kong I, Park Y, Woo Y, Lee J, Cha J, Choi J, et al. Early epidemiological and clinical characteristics of 28 cases of coronavirus disease in South Korea. Osong Public Health Res Perspect. 2020;11(1):8-14.

14. Gandhi M, Yokoe DS, Havlir DV. Asymptomatic transmission, the Achilles' heel of current strategies to control Covid-19. Mass Medical Soc; 2020.

15. Bai $Y$, Yao L, Wei T, Tian F, Jin D-Y, Chen L, et al. Presumed asymptomatic carrier transmission of COVID-19. JAMA. 2020;323(14):1406-7.

16. Rothe C, Schunk M, Sothmann P, Bretzel G, Froeschl G, Wallrauch C, et al. Transmission of 2019-nCoV infection from an asymptomatic contact in Germany. N Engl J Med. 2020;382(10):970-1.

17. Qian $G$, Yang N, Ma AHY, Wang L, Li G, Chen X, et al. COVID-19 transmission within a family cluster by Presymptomatic carriers in China. Clin Infect Dis. 2020

18. Chan JF-W, Yuan S, Kok K-H, To KK-W, Chu H, Yang J, et al. A familial cluster of pneumonia associated with the 2019 novel coronavirus indicating person-to-person transmission: a study of a family cluster. Lancet. 2020; 395(10223):514-23.

19. Day M. Covid-19: identifying and isolating asymptomatic people helped eliminate virus in Italian village. BMJ. 2020;368:m1165.

20. Organization WH. COVD-19 WHO African region: external situation report 11. 2020.

21. Rodriguez-Morales AJ, Cardona-Ospina JA, Gutiérrez-Ocampo E, VillamizarPeña R, Holguin-Rivera Y, Escalera-Antezana JP, et al. Clinical, laboratory and imaging features of COVID-19: a systematic review and meta-analysis. Travel Med Infect Dis. 2020:101623.

22. Young BE, Ong SWX, Kalimuddin S, Low JG, Tan SY, Loh J, et al. Epidemiologic features and clinical course of patients infected with SARSCoV-2 in Singapore. JAMA. 2020;323(15):1488-94.

23. Grasselli G, Pesenti A, Cecconi M. Critical care utilization for the COVID-19 outbreak in Lombardy, Italy: early experience and forecast during an emergency response. JAMA. 2020;323(16):1545-6.

24. COVID C, Team R. Severe outcomes among patients with coronavirus disease 2019 (COVID-19)—United States, February 12-march 16, 2020 MMWR Morb Mortal Wkly Rep. 2020;69(12):343-6.

25. Day M. Covid-19: four fifths of cases are asymptomatic, China figures indicate. Br Med J Publish Group. 2020.

26. Nishiura H, Kobayashi T, Miyama T, Suzuki A, Jung S, Hayashi K, et al. Estimation of the asymptomatic ratio of novel coronavirus infections (COVID-19). medRxiv. 2020

27. Gupta N, Agrawal S, Ish P, Mishra S, Gaind R, Usha G, et al. Clinical and epidemiologic profile of the initial COVID-19 patients at a tertiary care centre in India. Monaldi Archives for Chest Disease. 2020;90(1).

28. Mclntosh K. Coronavirus disease 2019 (COVD-19). 2020] Disponível em: https:// www.uptodate.com/contents/coronavirus-disease-2019-covid-19-epidemiologyvirology-clinical-features-diagnosis-and-prevention Acesso em. 2020;30.

29. Zhou F, Yu T, Du R, Fan G, Liu Y, Liu Z, et al. Clinical course and risk factors for mortality of adult inpatients with COVID-19 in Wuhan, China: a retrospective cohort study. Lancet. 2020.

30. Grasselli G, Pesenti A, Cecconi M. Critical care utilization for the COVID-19 outbreak in Lombardy, Italy: early experience and forecast during an emergency response. Jama. 2020.

31. Onder G, Rezza G, Brusaferro S. Case-fatality rate and characteristics of patients dying in relation to COVID-19 in Italy. JAMA. 2020.

32. Health Mo. PRESS STATEMENT - Update on the COVID-19 response in Uganda Kampala. 2020 [cited 2020 May 27, 2020]. Available from: https:/uccinfo.blog/2 020/04/02/press-statement-update-on-the-covid-19-response-in-uganda/.

33. Aceng JR, Ario AR, Muruta AN, Makumbi I, Nanyunja M, Komakech I, et al. Uganda's experience in Ebola virus disease outbreak preparedness, 20182019. Glob Health. 2020;16(1):1-12.

34. Lam P-P, Coleman BL, Green K, Powis J, Richardson D, Katz K, et al. Predictors of influenza among older adults in the emergency department. BMC Infect Dis. 2016;16(1):615.

35. Sayers G, Igoe D, Carr M, Cosgrave M, Duffy M, Crowley B, et al. High morbidity and mortality associated with an outbreak of influenza a (H3N2) in a psycho-geriatric facility. Epidemiol Infect. 2013;141(2):357-65.

36. Park S, Choi GJ, Ko H. Information technology-based tracing strategy in response to COVID-19 in South Korea—privacy controversies. JAMA. 2020

37. Lee VJ, Chiew CJ, Khong WX. Interrupting transmission of COVID-19: lessons from containment efforts in Singapore. J Travel Med. 2020;27(3).

\section{Publisher's Note}

Springer Nature remains neutral with regard to jurisdictional claims in published maps and institutional affiliations.
Ready to submit your research? Choose BMC and benefit from:

- fast, convenient online submission

- thorough peer review by experienced researchers in your field

- rapid publication on acceptance

- support for research data, including large and complex data types

- gold Open Access which fosters wider collaboration and increased citations

- maximum visibility for your research: over $100 \mathrm{M}$ website views per year

At BMC, research is always in progress.

Learn more biomedcentral.com/submissions 